\title{
The Dynamics of Being Alone and Stressed: Pakistani Female Doctoral Students' Experiences and Coping Strategies while Pursuing Higher Education in Malaysia
}

\author{
Syed Faisal Hyder Shah ${ }^{1}$, Abdul Razaque Channa ${ }^{2}$ and Musharaf Ali Talpur ${ }^{3}$
}

\begin{abstract}
This paper explores the complex nuances and experiences of international female doctoral students when they are in the 'settling-in phase' to their new (host) country of higher education. When coming to Malaysia as international students, they experience feelings of being outside of their country of origin. Being physically away from their loved ones, they constantly feel stress, loneliness and homesickness. To overcome these challenges, it is especially important for the international students to surmount their first few months in the host country's communities. To achieve these results, the study employs a qualitative methodology underpinned by symbolic interactionism to elicit the true significance of these Pakistani female doctoral students' social interactions with the host country's community. Based on our findings, we established that female doctoral students involve themselves in a variety of coping strategies keeping in view the new environment of a host country and their adjustment to it, such as binge-watching, social network sharing, faithbased activities, going to the gym, routine management and travel and outing.
\end{abstract}

Keywords: International Students; Environment; Coping Strategy; Pakistan; Malaysia.

\section{Introduction}

International students, specifically female doctoral students, are non-citizens living temporarily in the host country, which is other than their own country of citizenship or origin, for the purpose of education (UNESCO, 2006). Putting differently, international students are a group of individuals in an alien land, with a bundle of challenges, which include social adjustment, education, new environment, food, different culture, and the resulting loneliness and homesickness. According to Koehne (2005), international students are a diverse group of individuals, who are always expressed in the literature as an entity rather than individuals with their personal experiences and histories. Apart from the economic cost, international students make significant opportunity cost (or benefits forgone) in terms of leaving behind families, colleagues, and loved ones to pursue higher education for the sake of their dreams and future career. Thus, international students acquire different

\footnotetext{
${ }^{1}$ Department of Social Work, University of Sindh, Jamshoro, Sindh, Pakistan.

${ }^{2}$ Department of Anthropology and Archeology, University of Sindh, Jamshoro, Sindh, Pakistan.

${ }^{3}$ Abida Taherani Sindh Development Studies Centre, University of Sindh, Jamshoro, Sindh, Pakistan.
}

*)Corresponding Author.

Email: razaque.channa@usindh.edu.pk 
perspectives, gain respect and self-esteem, and begin to socially mature as a consequence of their independent life experiences when living in their host country with a different culture (Sherry, Thomas, \& Chui, 2010).

According to Baklashova \& Kazakov (2016), international students most often face a series of transitional difficulties immediately after arriving to the host county. These difficulties are broadly categorized as academic, social and cultural. In the first instance, international students confront the ethnocultural diversity. For some students, it is an opportunity to enrich the cultural diversity with their own culture and ethnic background. For others, it is a sense of loneliness and cultural shock intellectually maneuvered by their past behaviour and experiences, which leave them with little opportunities to socialize and near-zero social skills. In a broader perspective, international students' survival abilities are often put to the test when they encounter more obstacles in the host country than in their home country. These obstacles are, but not limited to, different food, unfamiliar living conditions, financial problems, the imbalance between studies and work. As a result, they have to mentally fit themselves into the schedule of classes, learning styles, and other possible difficulties related to language, culture, and personal barriers, which creates quite a stressful situation while pursuing higher education abroad. For example, a normal average student encounters a number of difficulties as mentioned above starting from the transitional period (i.e. everyday situations in daily life) to cultural adaptation (i.e. social understandings with the communities in a host country).

Principally, international students feel stressed when they move for the first time to the host country and experience stress all the time. Among the many factors, culture shock is one of the most common experiences for students who have moved from their native culture to another, which make them feel disoriented when experiencing an unfamiliar way of life. Furthermore, culture shock manifests itself in a variety of ways, including homesickness, loneliness, isolation, disorientation, sadness, and sleeping and eating disorders.

\section{Literature Review}

Poyrazli, Arbona, Bullington, and Pisecco (2001) discovered that foreign students who were psychologically dependent on their parents and relatives were more susceptible to homesickness when going to the host country for the purpose of higher education. Consequently, they often remain in constant tension and feel less confident which further lead them to be confused and socially isolated. They neither enjoy academic life nor have fun with their colleagues. These conditions interfere with their adjustment to the culture of the host country. Besides, as Cadman (2000) said, there are still many unexplored areas of international student's vulnerabilities. In this direction, Yeh and Inose (2003) also conducted an extensive study interviewing 372 international undergraduate students from 77 countries in an urban University in the northeastern part of the USA. They found that international students 
confront many challenges due to language and cultural barriers, academic and financial difficulties, interpersonal problems, racial discrimination, loss of social support, alienation and homesickness.

When dealing with various challenges being confronted by the female doctoral students, social support networks for international students play a vital role in coping and dealing with stress and mental health concerns (Patron, 2014; Brown \& Holloway, 2008; C. Yeh \& Wang, 2000; Mori, 2000; Cross, 1995). According to Patron (2014), the establishment of social support networks is unquestionably one of the most valuable and useful strategies that international students can adopt to adjust successfully to the host culture and society. Cross (1995), emphasizing the need for support groups, concluded that students who socially rely on others, for example, their friends and colleagues, rather than parents tend to prefer close alignment (or harmony) with others and tend to change themselves in accordance with the changing the environment. Thus, they accept the situations and change their social behaviour and expectations accordingly. Misra and Castillo (2004) in their study explained that an abundance of academic tasks combined with time constraints puts students under increased pressure and eventually causes them to experience stress. The authors further clarified that a rise in stress volume reduces an individual's ability to cope and re-adjust and concluded that as the stressors accumulate, they hinder individuals' ability to adjust and influence it negatively, resulting in their reduced physical or psychological reserves, called a 'coping mechanism'. Sooner or later, the development of physical illness or psychological distress becomes unavoidable.

Coping mechanisms and styles vary according to culture and gender (Misra \& Castillo, 2004; Khawaja \& Stallman, 2011). The authors previously discovered that male students experience more stress than female students. According to Khawaja and Stallman (2001), coping styles also differ between cultures; for example, Asians are less inclined to seek or avoid professional help and use other alternative escaping and passive coping strategies. These strategies often land them in the grip of pessimistic thoughts and values, exacerbating their tension. As a consequence, foreign students have recorded psychiatric difficulties such as depression and anxiety with adverse physical symptoms, such as appetite loss, nausea, and insomnia (Mori, 2000).

According to Khawaja, White, Schwetizer, and Greenslade (2008), religious beliefs and practices can also help provide several coping strategies. The authors found a correlation between faith values and coping mechanisms that increases student's patience and his/her expectations for a better future. Moreover, religious beliefs help individuals adapt to a new culture and strengthen them to face difficulties. Lazarus and Folkman (1984) defined coping as a person's constantly changing cognitive and behavioural efforts to manage her/his demands that are measured as difficult or beyond the person's resources and abilities. The authors further defined three features of this definition; the first is the process-oriented meaning that focuses on what the person thinks in an actual stressful encounter. The second is a contextual 
meaning, where a person acts and shapes its coping efforts situationally. Finally, in a third definition, the authors defined that; no prior assumptions can be furnished that constitute good or bad coping.

Folkman, Lazarus, Dunkel-Schetter, DeLongisand Gruen (1986), in their study, found that coping was differently related to satisfactory or unsatisfactory encounter outcomes. The authors discussed two types of coping, i.e., trait-oriented and process-oriented. The authors further described that in a trait-oriented approach coping is assumed a prime property of a person. There is little importance in stressful situations, whereas in a process-oriented approach, coping is assessed as a response to specific encounters' psychological and environmental demands. The authors concluded that the difference between the two is based on the "significance given to the psychological and environmental context in which coping takes place" ( $p$. 992). Support of Significant other is vital in most of the cases, significant other is a person who has great importance to an individual's life or who have a strong influence on an individual's self-concept. Holt (2012) described that significant others play an important role in a person's life and success. A person cannot possibly choose to study in university without any support, on their own in all the cases, especially of those who contribute to the person's identity-making as is the case of female students in Pakistan. The author further said that a supporting person could be a mother, father, siblings, teacher, or friend, but support plays an important role. Hall (1996 said that significant others, have provided exceptional support for women in the critical times of their careers. In most cases, the husband, a colleague, friends, and in some cases, the nannies who provided childcare and household support have served as significant others. Moreover, these significant others have provided the women essential support in their perusal of success.

In their analysis of successful women in Pakistan, Noreen and Khalid (2012) found that almost all of the women who took part in the study believed that their performance was primarily due to the continuous help of their father, mother, brother, and husband. During the era when society was much conservative and against women's education and employment, these "significant others" played a key role in encouraging potential women to break the restraints and move ahead to success.

\section{Methodology}

The present study investigates the challenges, motivations, coping strategies, and experiences of Pakistani female doctoral students pursuing higher education in selected Malaysian public universities. Strauss and Corbin's (1990; 1998) formal Grounded Theory approach was implemented to undertake our research study (Syed, Talpur \& Shaikh, 2018; Syed, Talpur \& Channa, 2019). This study, therefore, adopts a qualitative approach with the underpinning of the Symbolic Interactionism of Herbert Blummer (1969). The primary data were collected from 30 female doctoral students from five public universities of Malaysia. Semi-structured face-to-face interviews were 
conducted. All the ethical procedures and protocols were followed before and during the interviews. After gathering the email addresses of proposed respondents from Pakistani student groups of different public universities, the invitation forms were sent through emails to 44 Pakistani doctoral female students. The primary data collection source was a series of semi-structured face-to-face interviews with 30 Pakistani female doctoral students, who finally agreed to participate in the interviews. The data were also supplemented by the memos and field notes taken by the researchers. The data were analysed in a three-step coding and analysis process, namely Open, Axial, and Selective coding, using Strauss and Corbin's systematic Grounded Theory (1990). The data were analysed using the constant comparative method of Glaser and Strauss (1967). Additionally, NVivo 11 Pro was used to present the analysis intensely through visualization (Syed et al., 2018; Syed et al., 2019).

The present study found some new ways of coping while applying the theoretical foundations in the symbolic interactionism of Herbert Blumer, which according to Blumer (1956) suggested that we should look upon "human life as chiefly a vast interpretative process in which people, individually and collectively, guide themselves by defining the objects, events, and situations which they encounter (p. 686)." As Blumer (1969) said that different meanings can arise in the process of interaction between people, and can further be understood accordingly:

...the meaning of a thing for a person grows out of the ways in which other persons act towards the person with regard to the things. Their actions operate to define the person. Thus, symbolic interactionism sees meanings as social products, as creations that are formed in and through the defining activities of people as they interact (p. 4-5).

Charon (1992) elaborated on the notion of an individual's interpretive process by stating that each personality perceives truth differently and has a distinct personal reality that unique reality may not emerge in a void. Furthermore, the author explained that it is derived from and founded on the social realities that emerge as a result of contact with others.

\section{Analysis and Discussions}

\section{Coping Strategies}

Coping strategies differ according to the condition and the environment. The respondents of this study are female doctoral students who are in pursuance of their highest degree. The majority of the time, doctoral students are depressed for a variety of factors: personal, social, and academic in nature, as well as others. Thus, this is how they address the difficulties of their voices. The verbal accounts of study respondents on coping strategies. 


\section{Social Networking}

When we discussed the difficulties associated with international exposure, isolation, homesickness, and other stressors were mentioned as contributing to the respondents' mental distress. We also consider the modern technologies and ways that have very much reduced if not completely vanished these challenges and feelings. Social networking and communication have made considerable advancements that have almost bridged the gap of communication. The respondents, M3, U13, G1, and S1, have echoed that the latest technologies and smartphones have bridged almost all communication gaps.

A respondent $\mathrm{S} 1$ appreciated social media resources and considered it a good thing in this era to help loneliness. She thinks loneliness is a thing of the past now. She said it was in the earlier ages when there was too much communication gap. She further said they now have Skype, IMO, WhatsApp, Viber, Facebook, and many other social networking apps to communicate with our loved ones. In her opinion, social media has played a significant role. New features and apps have broken all the barriers and got us connected with our family and loved ones all the time. According to her, smartphones have changed the lives of individuals. We can share each moment of our life on social media with our friends and family.

...thanks to modern technology and free communication, now you don't miss your loved ones that much. My husband and my daughter are here, but I still miss my mother, father, siblings, and laws, so whenever I miss them, I call them on WhatsApp or Skype. [Respondent U13]

5.1 Social Updates: Many respondents reported that they felt more comfortable after uploading images to Facebook and updating their status. It reintroduces them (respondents) to their loved ones and makes them excited to share their experiences with them. Respondents S6 and U4 further added that it also has the reverse impact when people discourage you and negatively comment on your status. They said sometimes it ruins the mood and makes them sad. On the contrary, U4 and U10 respondents believed that postings and status updates work only for the honeymoon period for the initial few months. They feel that postings and status updates consume too much time, which ultimately distracts and hinders their work progress.

A respondent S3 informed that she posts sometimes and gets the comments, but it depends on what she posts. If your post is relevant to your research, such as conference or seminar participation, the majority of responses would be encouraging in nature, such as "well done" or "keep it up," and some will even offer you prayers. On the contrary, when you post photos of tourist places like beaches or while shopping, you get mixed comments, negative, positive, jealous, and some people start to lecture that you are there to study and do PhD rather than wasting time in leisure activities. She said 
people on social media use to advise her "to focus on what you are there for." However, her parents always encourage her to go out and have some shopping, travel and explore Malaysia. She emphasized that you lived 3 to 4 important years of your life in a different country to explore it and get maximum out of it. She added that she posts personal stuff with a privacy setting and does not post too many things or share too many things with the public.

... social media helps a lot in the adjustment; when I see my family members posting pictures on Facebook, I feel very happy. When I post photos on Facebook, my friends, relatives, and family members like my photos and give comments, those comments make my day, and I feel very happy, and I use to see the comments again and again and get happy. I feel their love! when I see their positive comments on my photos and posts. When you are alone and homesick and get positive comments on your postings and photos, the comments play a catharsis role, a healing role that helps. It is a kind of appreciation. As a student, you are doing so much hard work and struggle, and your loved ones and relatives appreciate you. I feel more energetic and charged by reading the comments. [Respondent U7]

5.2 Surfing Smartphones: It was highlighted that smartphone usage also helped the respondents shy away from anxiety and boredom. As many of the respondents shared that net surfing for no reason makes them concentrate less on their worries and engage them in socialization which helps them to relax. Some of them also noticed that they are consuming more time than usual or spending more time surfing smartphones than when they were at home in Pakistan.

A respondent S1 stated that surfing Facebook for no reason was also a helping tool to keep self-engaged when feeling down, as scrolling up and down, coming across many posts shared by your friends makes you feel calm and connected. She mentioned that the usage of smartphones had also increased a lot since she was in Malaysia.

...I have noticed that my smartphone usage has increased here in Malaysia. I have been using a smartphone for 3 years, but when I was at home, I used to use hardly 15 minutes in a day except calling, but I use it a lot here. I use many applications, and I think it's also a coping strategy to engage yourself (laugh). Whenever I feel bored or do nothing, I pick my phone and scroll up and down. [Respondent S3] 
5.3 YouTube and Entertainment: Another intriguing explanation for smartphone use was television, specifically watching Pakistani soap operas and dramas on YouTube. Few respondents believed that watching serials and programs on YouTube makes them feel happy. As a woman, they enjoy these soap dramas, and often it is the topic of discussion when they meet (Pakistani women).

A respondent M3 shared that she also misses Pakistani dramas, so she watches them on YouTube. She was watching a play in which a man marries two women; she said that situation put her under too much stress, as her husband was in Pakistan. She said she suddenly got worried about him as he was alone, and if he marries another woman what will happen to her (ha halaugh). Anyways she watches them (soup serials) and to her "they are the great source of my entertainment in Malaysia."

S5 respondent said they always talked about dramas and new serials when she meets with her Pakistani friends. She also discusses TV shows with her siblings on Skype and WhatsApp. She added that you can watch your favourite country program on YouTube which gives you a feeling that even though you are far away from your home, you are still connected with your culture and other things.

...the other thing I use to do to keep my stress away is watching movies a lot. Let me sit at home, and I can watch three movies a day, and it makes me feel good. [Respondent G4]

5.4 Listening to Music: In addition to using the gym and physical activities, listening to music has also proven to be effective for these respondents as one of the coping strategies. Most of them shared that they tend to listen to music whenever they are deep down under stress.

U2 respondent stated that she does exercise to keeps herself fit. However, when she gets so much stressed, she listens to music. A respondent U11 said when she feels too lonely, she goes out and then plays party music in full volume on hands-free. It makes her feel very relaxed. However, she said sometimes, when you are in deep stress because of your workload, you cannot play music even at a slow volume.

...I used to console myself to be silent and go to the gym and exercise to cope with my stress. Sometimes I also listen to music. [Respondent U7].

\section{Sports, the Gym}

Physical practices such as brisk walking, jogging, cycling, exercising, and going to the gym often proved to be beneficial for healing and coping mechanism. As many of the respondents mentioned, walking and jogging in the lush green surroundings of Malaysian campuses make them feel close to 
nature. Closeness with nature is a great source of mediation and coping when you are under stress. A respondent G5 said that she goes to the gym, but mostly, she goes for a walk. When strolling around this lovely campus, I observe that butterflies are fluttering and birds are singing; which makes her feel as if she is in paradise. These exuberant feelings bring her much pleasure and serves as a useful tool for socialisation.

U8 respondent shared that sometimes when she takes too much stress, she even cannot talk properly because her blood pressure gets down, and she feels dizziness. Then, she starts physical exercise, which helps her. She further informed that she has started playing lawn tennis, and since then she felt improvement in her blood circulation. So, she feels good after playing and then feels relaxed. A respondent U1 mentioned that she had made a schedule for everything to keep herself busy. She also informed that she walks 4 kilometers daily in the evening, however, when she observes many nice events taking place around her, such as children playing in the parks and people enjoying their life, it helps her to turn her mind away from her troubles that eventually make her feel at ease. She thinks if she stays in her room, she will only eat and put on weight; thus, it is better to go out and exercise.

\section{Religious Practices}

One of the respondents S3 said,

...Prayers release the level of depression and help us to concentrate on the solutions because when you are calm, you can think about the solutions. [Respondent S3]

A respondent U10 elaborated that faith (or religious) rituals were the most effective means of coping with depressive emotions. They get closer to Allah (God). Allah would undoubtedly assist you in relaxing. Only prayers and faith traditions, she says, have saved her and gotten her out of any crisis.

...All other things only work for a time, but regular prayers and the recitation of the holy Quran keep me getting motivated and strong. It gives me the feeling of completeness [Respondent U10].

One of the respondents, U8, got a divorce from her husband; she was devastated and felt her life had been distorted. On the verge of changing her life and environment, the respondent started a new life and took admission in Ph.D. and came to Malaysia. Though this study revolved around the process and challenges of the Pakistani female doctoral students, it has also explored respondents' backgrounds and painful stories. She shared her story that how she managed to escape from a conservative society like Pakistan. She stated that there was hardly any life for a divorced woman. She shared how faith in Allah has given her the strength to face her life's challenges and hardships. She mentioned that she was given advice from her Ustaz (religious mentor) to 
recite the holy Quran with translation, which helped her a great deal. She expressed that she blamed herself for her condition, as other people from society blamed her. She said that "Allah has helped me overcome my situations and gave me the strength to face my challenges".

One of the respondent respondents, S1, considers herself secular and followed the religious practices only when she was in deep stress. She acknowledges that religious practises preserve a person's dreams, as she claimed that she recalls having a disagreement with her ex-supervisor. She was so much stressed and disturbed that having no faith in religion, she went to the mosque to pray (laugh). According to her, it is all psychological, whether a believing individual view it as a miracle or a person like her views it as a simple coincidence.

...the first thing I do to relax my stress is that I use to offer prayers, communicate with Allah (God) whatever struggle I am in or whatever hardship I face; I use to offer prayers and recite Holy Quran. I pray and ask Allah to help me ease my problems. Salah (Prayer) is natural yoga, and I think it's meditation [Respondent M1].

I also use to perform religious practices and recite the Holy Quran as it keeps me calm and helps me spiritually to cope with my challenges. [Respondent U13].

\section{Busyness}

The respondents shared many other interesting ways of coping with loneliness and homesickness, and other stressors. Among others, one was to keep themselves busy with many things so that they have no time to think about their worries anymore.

A respondent $\mathrm{U} 1$ mentioned that she has kept herself so occupied with her research, colleagues, and other hobbies that she no longer feels lonely. She has made a schedule for everything now, to keep herself busy and to get herself adjusted. According to her, the schedule was so tough that when she gets back to the room, she feels tired and goes to sleep within no time; thus, she doesn't think of her loneliness (laugh).

...I kept myself busy with my studies all the time, and I use to spend all my day at my lab. I motivate myself to study more and more as there was no one at home. When I use to remain at home, the home's emptiness uses to haunt me so, I kept myself busy at the lab all the time till noon. [Respondent M3].

\section{Socialization}

Socialization is highlighted as the best ways of coping and adjusting in a foreign land. The company of like-minded people always provide cosiness and comfort. You share your ideas, feelings, likes, and dislikes with your friends 
and in return, you feel like you are in the right place. The respondents S3 and U1 said that they prefer to socialize with other Pakistani girls as they can speak the same language, which according to them (respondents), pleases their tongue. For S6 and U2 respondents, it was a different case as they don't bother to find friends from their own country. Their basic aim is to socialize and get some knowledge from other nationals, cope with their challenges, and look more for coping and adjustment strategies.

One of the respondents, S6, also shared that her university's postgraduate association has helped her a lot by providing her with the platform where she can meet different national and international students. She said that interacting with other nationals taught her many things about new ways of coping and dealing with common challenges.

S5 respondent expressed that sometimes when you get the company of similar interests, it helps manage homesickness and cope. The adjustment, particularly related to food and friends, was the main source of adjusting. She suggested the best coping strategy was to make more friends and spend weekends with them to feel better. A respondent U3 thinks that socializing and making friends helped her greatly in coping. She shared that all her friends discuss their problems with each other, and by oozing out their problems, they feel light and relaxed. She further added that they also try to figure out the possible solutions to the problems, and most importantly, with patience, she relaxes.

A respondent $\mathrm{S} 2$ said she was so stressed about her loneliness that she used to talk to the people passing by, with strangers and with the hostel staff and whosoever she was seeing. She said she misses her mother a lot. Then she found a Pakistani girl and they become good friends.

...I think socialising is the best idea; I used to go to friends when I feel too stressed or worried. I use to share my problems with my friends to ease my stress [Respondent U6]

\section{Travel and Outing}

Travelling and outing is also a useful strategy for many of the respondents of the present study. The respondents feel they can get some time out to review and rethink their strategies and relax. A respondent S8 thinks that going out most of the time is not good as it gives her a negative feeling. For U11 respondent, nothing works when a person is under stress as she thinks that when a person under the stress of workload, he/she is unable to enjoy her life.

One of the respondents, G5, shared that she does her catharsis herself; it was her own decision to come here, so now she must cope. She said she uses to relax by travelling to different places in Malaysia, roaming here, and relaxing her stress. U10 respondent explained that when she is too stressed by work, they plan for an outing. She believes that outings are the perfect way to alleviate tension and they help to calm your mind and have a break from your worries and stressors. She believes that occasionally resting the mind is 
beneficial because it aided her greatly in refocusing and rethinking her plans for going ahead.

...to cope with the feeling of loneliness we travel a lot and use to go out every weekend. We try to enjoy and explore Malaysia as well. [Respondent G1]

\section{Routine Management}

According to respondent M1, time management is the best way to make yourself calm and relax. In her opinion, "mostly we waste our time in useless things which later becomes a guilt and burden for ourselves." She shared that she has made her schedule of doing all the housekeeping and cooking on Saturdays, and she spends the whole Sunday outing with her son and spending quality time with him.

...when there are too much stress and problems, I use to sleep and take rest. I think sleep makes me forget about my problems, and I use to get relax. When you are under stress and cannot think how to get out of your stress, the best thing is to rest a while and sleep. The mind gets some rest, and you can concentrate and think properly about the solutions; that is my way of dealing with problems. [Respondent U13]

\section{Conclusions}

Our research study analysed the experiences and coping strategies of Pakistani female doctoral students when they feel stressed and loneliness while pursuing higher education in Malaysian public universities. This study used a 'Grounded Analysis Method' to gather primary data through face-to-face interviews with Pakistani female doctoral students. After a detailed qualitative research analysis, we argue that international exposure has altered respondents' lives as a result of their struggles and successes. They developed greater strength and resilience as a consequence of their experience of living during tough periods beyond their nation and being alone. However, respondents reported experiencing a variety of difficulties varying from psychosocial to personal in nature, including personal prejudices, bigotry, culture shock, financial restrictions, language barriers, food, environment, homesickness, and isolation, as well as interpersonal and social relationship difficulties. Furthermore, the support system plays a critical role in assisting international students, especially during their transition process. For instance, it must garner support from local students, residents, teachers, scholars, the university, colleagues, Pakistani Student organisations, and other international students.

The freedom to socialize and mingle with others strengthened Pakistani female doctoral students in relieving academic pressure and seeing life in new ways. Respondents' coping strategies differed according to their culture and the challenges they encountered in their respective fields and universities. Smartphones and social networking sites were listed as the most 
sophisticated resources for combating boredom, anxiety, and isolation by the majority of respondents. Our study proves that commitment to faith and social traditions was the significant source of coping mechanism in dealing with the loneliness and managing the stress. Many respondents feel that by being apart from their family, they have become closer to God (Allah).

Finally, keeping oneself academically busy and physically active proved successful at times of immense stress. Travelling to tourism destinations and visiting nearby cities allowed them to refocus on their studies, simultaneously, it helped them rejuvenate and maintain their productivity.

\section{References}

Baklashova, T. A., \& Kazakov, A. V. (2016). Challenges of International Students' Adjustment to a Higher Education Institution. International Journal of Environmental and Science Education, 11(8), 1821-1832.

Blumer, H. (1956). Sociological analysis and the variable. American sociological review, 21, 683-690.

Blumer, H. (1969). Symbolic interactionism; Perspective and method. New Jersey US: Prentice-Hall.

Brown, L., \& Holloway, I. (2008a). The adjustment journey of international post-graduate students at an English university An ethnographic study. Journal of Research in International Education, 7(2), 232-249.

Brown, L., \& Holloway, I. (2008b). The initial stage of the international sojourn: excitement or culture shock? British Journal of Guidance \& Counselling, 36(1), 33-49.

Cadman, K. (2000). 'Voices in the air': evaluations of the learning experiences of international postgraduates and their supervisors. Teaching in higher education, 5(4), 475-491.

Charon, J. (1992). Symbolic interactionism: An introduction, an interpretation, an integration (4th ed.). New jersey 07632, USA: Prentice-Hall,Inc.

Chirkov, V., Safdar, S., De Guzman, J., \& Playford, K. (2008). Further examining the role motivation to study abroad plays in the adaptation of international students in Canada. International Journal of Intercultural Relations, 32(5), 427-440.

Folkman, S., Lazarus, R. S., Dunkel-Schetter, C., DeLongis, A., \& Gruen, R. J. (1986). Dynamics of a stressful encounter: cognitive appraisal, coping, and encounter outcomes. Journal of personality and social psychology, 50(5), 992.

Hall, V. (1996). Dancing on the ceiling: A study of women managers in education. UK: Sage Publications UK.

Holt, B. (2012). Identity matters: the centrality of 'conferred identity'as symbolic power and social capital in higher education mobility. International Journal of Inclusive Education, 16(9), 929-940. 
Khawaja, N. G., \& Stallman, H. M. (2011). Understanding the Coping Strategies of International Students: A Qualitative Approach. Australian Journal of Guidance and Counselling, 21(02), 203-224.

Khawaja, N. G., White, K. M., Schweitzer, R., \& Greenslade, J. (2008). Difficulties and coping strategies of Sudanese refugees: A qualitative approach. Transcultural psychiatry, 45(3), 489-512.

Koehne, N. (2005). (Re) construction: Ways international students talk about their identity. Australian Journal of Education, 49(1), 104-119.

Mori, S. C. (2000). Addressing the mental health concerns of international students. Journal of Counseling \& Development, 78(2), 137-144.

Noreen, G., \& Khalid, H. (2012). Gender Empowerment through Women's Higher Education: Opportunities and Possibilities. Journal of Research and Reflections in Education, 6(1), 50-60.

Patron, M.-C. (2014). Loss and Loneliness Among International Students. Psychology Journal, 11(1).

Poyrazli, S., Arbona, C., Bullington, R., \& Pisecco, S. (2001). Adjustment issues of Turkish college students studying in the United States. College Student Journal, 35(1), 52-52.

Sherry, M., Thomas, P., \& Chui, W. H. (2010). International students: A vulnerable student population. Higher Education, 60(1), 33-46.

Strauss, A., \& Corbin, J. (1998). Basics of qualitative research: Techniques and procedures for developing grounded theory ( $2 \mathrm{nd}$ ed.). California 91320, USA: SAGE Publications, Inc.

Strauss, A., \& Corbin, J. M. (1990). Basics of qualitative research: Grounded theory procedures and techniques. USA: Sage Publications, Inc.

Syed, F. H. S., Talpur M. A., \& Shaikh, I. A. (2018), Factors Influencing Muslim International Students to Choose Malaysian Public Universities for Higher Education: A Case Study of Pakistani Female Doctoral Students', Asia Pacific Journal of Fareast and South East Asia, 36, 127-144

Syed, F. H. S., Talpur M, A., \& Channa, A. R (2019), Push and Pull Factors of International Higher Education: A Case Study of Pakistani Female Students Studying in Malaysia, Asia Pacific Journal of Fareast and South East Asia, 37, 102-125,

UNESCO. (2006). Global Education Digest 2006: Comparing Education Statistics Across the World (9291890286). Retrieved from Montreal, Canada

Yeh, C., \& Wang, Y.-W. (2000). Asian American coping attitudes, sources, and practices: Implications for indigenous counseling strategies. Journal of College Student Development, 41, 94-103.

Yeh, C. J., \& Inose, M. (2003). International students' reported English fluency, social support satisfaction, and social connectedness as predictors of acculturative stress. Counselling Psychology Quarterly, 16(1), 15-28 